\title{
Commentary
}

\section{Distension in non-consulting dyspeptics: a swell idea}

Functional dyspepsia is a clinical syndrome defined by chronic or recurrent symptoms of pain or discomfort centred upon the upper abdomen without a cause being identified by conventional diagnostic means. ${ }^{1}$ The pathophysiology of functional dyspepsia is unknown but a number of mechanisms have been proposed, such as delayed gastric emptying, hypersensitivity to gastric distension, impaired accommodation to a meal, Helicobacter pylori gastritis, or central nervous system dysfunction.

Dyspeptic symptoms occur in approximately $25 \%$ of the general population and only about one quarter of these seek medical attention. ${ }^{2}$ The reasons underlying health care seeking behaviour in functional dyspepsia are unknown, and may relate both to symptom severity and psychological factors. ${ }^{2}$ Except for the possible involvement of $H$ pylori, the symptom pattern and underlying mechanisms in non-consulters with dyspepsia have received little attention. Recent developments of less invasive techniques, such as gastric emptying breath tests or a caloric satiety test, ${ }^{3}$ may facilitate studies in non-consulting subjects in the general population.

Because of its presumed pivotal role in the occurrence of functional gastrointestinal disorders, visceral sensitivity and its modulation is a topic of intense ongoing research. In this issue of Gut, Holtmann and colleagues used a gastric barostat procedure to study the sensitivity to repeated gastric distension in eight currently asymptomatic dyspeptic subjects who were non-consulters compared with eight asymptomatic age and sex matched controls, all of whom were $H$ pylori negative (see page 332 ). ${ }^{4}$ The selection of nonconsulting dyspeptic subjects was careful and thoughtful, adequately eliminating other causes of upper gastrointestinal discomfort. Assessment of visceral sensitivity using intragastric balloon distension in non-consulting dyspeptic subjects is an extremely challenging task, and the authors are to be commended for their endeavour.

In subjects with a history of dyspeptic symptoms, baseline thresholds for first perception were significantly lower than in asymptomatic controls. All subjects had a normal psychological profile. Although this observation might suggest that hypersensitivity to gastric distension is a mechanism underlying dyspeptic symptoms in nonconsulters, several issues must be taken into consideration.

In the past, differences in mechanosensory function have been reported for patients with functional dyspepsia as a group compared with normal controls. This approach has not allowed the emergence of a consistent correlation between symptoms and observed impaired function. More recently, it has become clear that functional dyspepsia should be considered a heterogeneous disorder where distinct pathophysiological abnormalities are present in subgroups of patients linked to specific symptom patterns. Thus delayed gastric emptying is present in one third of patients who are more likely to be female and to suffer from postprandial fullness and vomiting. ${ }^{5}$ Impaired accommodation is present in $40 \%$ of patients and is associated with symptoms of early satiety and weight loss. ${ }^{3}$ Hypersensitiv- ity to gastric distension was estimated to be present in about $50 \%$ of dyspeptic patients. ${ }^{67}$ Extrapolating from patients with functional dyspepsia who seek medical attention, it seems likely that non-consulting subjects with dyspeptic symptoms are a heterogeneous group also. Unfortunately, the paper by Holtmann et al provides only group means, and does not reveal the proportion of symptomatic subjects that were outside the range of normal, nor does it detail the type of symptoms they experienced.

Assuming a $50 \%$ prevalence of hypersensitivity to gastric distension, it seems surprising that a significant difference was found at baseline. This may be partly explained by the method used to quantify perception thresholds. Although most barostat protocols use pressure increments as a driving stimulus, it is now clear that activation of gastric tension receptors is required to generate perception. ${ }^{8}$ Only intraballoon pressures higher than the intra-abdominal pressure (termed the minimal distending pressure, MDP) can distend the stomach, and hence activate tension receptors. Consequently, thresholds are preferably expressed as pressure increments above $\mathrm{MDP}^{36}$ Moreover, patients with functional dyspepsia are likely to have a lower intra-abdominal pressure as they often have a lower body mass index. ${ }^{5}$ It is unclear in the present paper, where MDP was $1.5 \mathrm{~mm} \mathrm{Hg}$ lower in subjects with a history of dyspepsia, whether expressing baseline threshold perception pressures relative to MDP would still have generated a significant difference in baseline threshold.

Regardless of baseline perception thresholds, the response to repeated distensions was strikingly different in dyspeptic versus control subjects. In control subjects, sensory thresholds increased in response to repeated distensions while this tendency was absent in dyspeptic subjects. In patients with irritable bowel syndrome (IBS), it has been reported that repetitive stimulation demonstrates sensory abnormalities more consistently than measurements of perception thresholds. ${ }^{9}$ An abnormal response to repeated distensions in both dyspepsia and IBS may well indicate dysfunction of descending inhibitory pathways. However, before considering absence of this sensory adaptation as a valid marker for functional dyspepsia, additional studies are required on larger numbers of consulting and symptomatic subjects.

Although altered visceral sensitivity is believed to play a key role in the development of symptoms in patients with functional gastrointestinal disorders, proving that symptoms are really attributable to altered sensitivity has remained problematic. ${ }^{9}$ In the present paper, hypersensitivity and abnormal adaptation to repeated mechanical stimuli were reported in non-consulters with dyspeptic symptoms. However, as all subjects were asymptomatic in the period preceding the barostat studies, it seems at least debatable that these disorders are directly involved in symptom generation. Moreover, if visceral hypersensitivity is responsible for induction of symptoms, lowering of discomfort or pain thresholds rather than of thresholds for first perception would seem to be more relevant. The thresholds for discomfort or pain, obtained during "ramp" distensions (that is, $2 \mathrm{~mm} \mathrm{Hg}$ increments, duration of each pressure step 30 seconds, maximum pressure $35 \mathrm{~mm} \mathrm{Hg}$ (or occurrence of pain)), did not seem to differ between non-consulting dyspeptic subjects and controls. 
In view of the heterogeneity of functional dyspepsia in consulters, eight subjects seems a very small group to draw firm conclusions on the characteristics of non-consulting dyspeptics. However, further characterisation of this population will help us to understand why dyspeptic subjects come to medical attention. In addition, the absence of sensory adaptation to repeated distension has the potential to be a relevant pathophysiological feature of functional dyspepsia and similar studies in symptomatic dyspeptic subjects are warranted.

Department of Internal Medicine, Division of Gastroenterology,

J TACK

University Hospital Gasthuisberg, University of Leuven,

Herestraat 49, B-3000 Leuven, Leuven, Belgium

Email:Fan.Tack@med.kuleuven.ac.be
1 Talley NJ, Stanghellini V, Heading RC, et al. Functional gastroduodenal disorders. Gut 1999;45(suppl II):37-42.

2 Talley NJ, Zinsmeister AR, Schleck CD, et al. Dyspepsia and dyspepsia subgroups: a population-based study. Gastroenterology 1992;102:1259-68. 3 Tack J, Piessevaux H, Coulie B, et al. Role of impaired gastric accommodation to a meal in functional dyspepsia. Gastroenterology 1998;115:1346-52.

4 Holtmann G, Gschossmann J, Neufang-Huber J, et al. Differences in gastric mechanosensory function after repeated ramp distensions in nonconsulters with dyspepsia and health. Gut 2000;47:332-6.

5 Stanghellini V, Tosetti C, Paternico A, et al. Risk indicators of delayed gastric emptying of solids in patients with functional dyspepsia. Gastroenterology 1996;110:1036-42.

6 Mearin F, Cucala M, Azpiroz F, et al. The origin of symptoms on the braingut axis in functional dyspepsia. Gastroenterology 1991;101:999-1006.

7 Camilleri M, Coulie B, Tack J. Visceral hypersensitivity: facts, speculations and challenges. Gut 2000 (in press)

8 Distrutti E, Azpiroz F, Soldevilla A, et al. Gastric wall tension determines Distrutti E, Azpiroz F, Soldevilla A, et al. Gastric wall tension determir
perception of gastric distention. Gastroenterology 1999;116:1035-42.

9 Munakata J, Naliboff B, Harraf F, et al. Repetitive sigmoid stimulation induces rectal hyperalgesia in patients with irritable bowel syndrome. Gastroenterology 1997; 112:55-63.

\section{Suicide and the not-so-innocent bystander}

As the field of anticancer gene therapy edges closer to the mainstream, so we learn more of its current limitations as well as the potential for future success. With the technologies available today, it is simply not possible to achieve correction of every single genetic abnormality in every malignant cell. Hence most approaches investigated so far have involved a cytotoxic strategy, aiming to selectively destroy tumours while avoiding "collateral damage" to normal tissues.

The success or failure of such cytotoxic gene therapy is influenced by two important choices-what therapeutic gene should be introduced and what vector should carry it to the target? We already have a range of genetic prodrug activation therapy (GPAT) strategies available, based on introducing tumour specific "suicide" enzymes that can generate toxic metabolites from otherwise benign prodrugs. Common examples include the herpes simplex virus thymidine kinase (HSVtk), which confers sensitivity to the antiviral drug ganciclovir, or the Escherichia coli derived cytosine deaminase that converts 5-fluorocytosine into the antineoplastic 5-fluorouracil (5-FU). ${ }^{2}$ Several other enzyme based systems are in development with the intention of either increasing tumour sensitivity to drug therapy or enhancing resistance of normal tissues to the side effects of anticancer agents. ${ }^{3}$

Each of the GPAT systems is capable of killing malignant cells effectively but only if they can be introduced into the appropriate target and expressed at a satisfactory level. The vectors currently available to us are unable to guarantee that every neoplastic cell will receive and express the transferred gene. As a result, anticancer gene therapies require augmentation of cell killing, either by approaches that cause an immune response against the tumour or by generating a "bystander effect". This latter term refers to the well recognised phenomenon of GPAT killing many more cells in a tumour mass than are actually expressing the therapeutic construct. ${ }^{4}$ In the case of 5-FU generation, the cytotoxic agent itself is able to diffuse into adjacent cells. With the HSVtk approach, the effect is mediated by intercellular gap junction communications. ${ }^{5}$

The other method of enhancing cell killing with GPAT is to recruit the power of the immune system. ${ }^{6}$ Immunotherapeutic strategies have, in their own right, made up the majority of anticancer gene therapy protocols and there is now further evidence that immune mediated approaches can be particularly effective in combination with GPAT. ${ }^{7}$ In particular, aggressive cytotoxic gene therapy can lead to enhanced systemic antitumour immunity if the mode of non-apoptotic cell death is rendered as immunologically "dangerous" as possible. ${ }^{8}$

In this issue of Gut, Lechanteur et al describe the effects of combining GPAT with the transfer of an immunostimulatory cytokine gene in a rat model of peritoneal carcinomatosis (see page 343). ${ }^{9}$ Tumour deposits were created by injecting $10^{6}$ cells of the DHD/K12 colorectal lineage into the peritoneum. After seven days of growth, the animals received weekly intraperitoneal injections of retrovirus producing cells expressing the HSVtk enzyme and either granulocyte macrophage-colony stimulating factor (GM-CSF) or interleukin 12 (IL-12) for a total of three doses. Ganciclovir was administered in a series of three day courses, beginning on day 10. The authors report that while HSVtk GPAT alone slightly increased the mean survival time from 63 to 72 days, addition of the cytokine genes significantly improved their results, with $60 \%$ of the GM-CSF group and $40 \%$ of the IL-12 cohort being tumour free after almost 16 months of follow up. Their successful response is attributed to a combination of prodrug activation, the bystander phenomenon, and the adjuvant effect of proinflammatory cytokines on the immune system.

These results are clearly encouraging although exactly how easy they will be to replicate in disseminated human cancer is another matter. Relatively small, one week old tumours are likely to pose less of a physical barrier to the penetration of viral vectors than large tumour masses. In the particular case of adenoviral gene therapy for intraperitoneal malignancy, immunohistochemistry and laser scanning cytometry have shown a depth of penetration of between 1 and 10 cells from the cell surface. ${ }^{10}$

Creating the conditions in which a high enough number of cancer cells express the therapeutic constructs and invoke bystander effects or immunological responses may require vectors with greater tumour selectivity. To this end, there has been renewed interest in the use of preferentially replicating bacteria that can colonise tumour deposits at concentrations orders of magnitude higher than in normal tissues. ${ }^{11}$ Such bacteria have a number of potential advantages over viruses. They are able to survive and multiply in the extracellular (as well as intracellular) microenvironment, are actively motile within tumour masses, and their relatively large size facilitates the carriage of multiple therapeutic constructs such as GPAT or immunostimulatory elements. ${ }^{12}$ 
Gene therapists can now arm themselves with a whole range of different cytotoxic strategies. In much the same way as "conventional" anticancer chemotherapy utilises multiple drugs acting on different targets, it seems the way forward will lie in finding the ideal combinations of vectors and therapeutic genes. ${ }^{13}$

R J ASPINALL

ICRF Molecular Oncology Unit,

Imperial College School of Medicine

Hammersmith Hospital, London W12 ONN, UK

Email:n.lemoine@icrf.icnet.uk

1 Vile RG, Russell SJ, Lemoine NR. Cancer gene therapy: hard lessons and new courses. Gene Ther 1999;6:2-8.

2 Springer CJ, Niculescu-Duvaz I. Prodrug-activating systems in suicide gene therapy. $\mathcal{F}$ Clin Invest 2000;9:1161-7.

3 Encell LP, Landis DM, Loeb LA. Improving enzymes for cancer gene therapy. Nat Biotechnol 1999;17:143-7.
4 Freeman SM, Abboud CN, Whartenby KA, et al. The "bystander effect": tumor regression when a fraction of the tumor mass is genetically modified. tumor regression when a fraction

5 Yang L, Chiang Y, Lenz HJ, et al. Intercellular communication mediates the bystander effect during herpes simplex thymidine kinase/ganciclovir-based gene therapy of human gastrointestinal tumor cells. Hum Gene Ther 1998; 9:719-28.

6 Sogn JA. Tumor immunology: the glass is half full. Immunity 1998;9:75763.

Aspinall RJ, Lemoine NR. Gene therapy for pancreatic and biliary malignancies. Ann Oncol 1999;10(suppl 4):188-92.

8 Todryk SM, Chong H, Vile RG, et al. Can immunotherapy by gene transfer tip the balance against colorectal cancer? Gut 1998;43:445-9.

9 Lechanteur C, Delvenne P, Princen F, et al. Combined suicide and cytokine gene therapy for peritoneal carcinomatosis. Gut 2000;47:343-8.

10 Grace MJ, Xie L, Musco ML, et al. The use of laser scanning cytometry to assess depth of penetration of adenovirus p53 gene therapy in human assess depth of penetration of adenovirus p53 gene

11 Pawelek JM, Low KB, Bermudes D. Tumor-targeted Salmonella as a novel anticancer vector. Cancer Res 1997;57:4537-44.

2 Sznol M, Lin SL, Bermudes D, et al. Use of preferentially replicating bacteria for the treatment of cancer. F Clin Invest 2000;105:1027-30.

13 Chung-Faye GA, Kerr DJ, Young LS, et al. Gene therapy strategies for colon cancer. Mol Med Today 2000;6:82-7.

\section{Dissecting out crytogenic liver disease}

The report from Pamplona in this issue of Gut gives insight into the spectrum of liver disease in Southern Europe and emphasises the importance of careful laboratory evaluation (see page 429). A total of 1075 consecutive patients who had undergone liver biopsy because of elevated transaminases were assessed retrospectively. In $90 \%$ of cases the cause was clear on conventional clinical and serological criteria: most commonly chronic viral hepatitis was responsible with hepatitis $\mathrm{C}$ predominating. The study focuses on the remaining $10 \%$ in whom the cause was not obvious, in particular using polymerase chain reaction (PCR) on stored serum to detect hepatitis viral sequences, and careful review of the biopsy specimens. The histological review showed cirrhosis in 13, chronic hepatitis in 39, non-alcoholic steatohepatitis (NASH) in 16, and non-specific changes in 33 patients.

The most important finding was the high prevalence of hepatitis B and C sequences, albeit at low levels: 19 patients had hepatitis B virus (HBV) DNA and nine had hepatitis $\mathrm{C}$ virus (HCV) RNA in their serum (one had both). None had evidence of HBV or HCV infection by conventional antigen/antibody testing although 30 had evidence of previous exposure to HBV. Sera from 59 seronegative blood donors of similar age were tested as controls and revealed one case each of HBV DNA and HCV RNA positivity. There was a strong correlation between cirrhosis/ chronic hepatitis and viraemia but none with serological evidence of past hepatitis B exposure. Thus of the starting cohort of 1075 patients with elevated transaminases, almost two thirds were eventually shown to have chronic viral hepatitis ( $\mathrm{C}$ being five times commoner than $\mathrm{B}$ ) of which a small proportion were surreptitious.

The problem of occult hepatitis infection and coinfection is increasingly recognised. Last year Cacciola and colleagues $^{2}$ in Sicily reported HBV sequences in the sera of one third of 200 patients with hepatitis C related liver disease all of whom were hepatitis $B$ virus surface antigen (HBsAg) negative. Most had antibodies to hepatitis B core antigen but a sizeable minority lacked any serological HBV markers. The occult nature of chronic hepatitis infection was taken a step further in a study from Edinburgh. ${ }^{3}$ Of 98 consecutive patients with antibodies to $\mathrm{HCV}$, there were 12 repeatedly negative for HCV RNA in serum by sensitive reverse transcription-PCR. However, 10 of these 12 were shown to harbour low levels of HCV RNA in liver tissue.

Surreptitious viral hepatitis infection has also been shown to play a crucial role in hepatocellular carcinoma (HCC). The European cooperative study reported by Brechot and colleagues ${ }^{4}$ in 1998 investigated hepatitis B and $\mathrm{C}$ in more than 500 patients with HCC from six European countries comparing serology with molecular testing. Conventional serology was positive for active hepatitis B and C infection in only $19 \%$ and $40 \%$ of cases whereas PCR detected genomic sequences of $\mathrm{B}$ and $\mathrm{C}$ viruses in $48 \%$ and $43 \%$, while $20 \%$ were infected by both.

The message from these observations is that conventional serology detects most cases of hepatitis $\mathrm{C}$ infection in chronic hepatitis, cirrhosis, and HCC but may miss $20-50 \%$ of cases of hepatitis B infection. PCR of serum will pick up most missed cases of viral infection depending on the sensitivity of the assay but PCR of liver tissue may be more sensitive still.

These data highlight the dominance of chronic viral hepatitis over other forms of liver disease in many parts of the world. ${ }^{5}$ Those working in areas where viral hepatitis is uncommon must take these reports in context. Occult hepatitis $\mathrm{B}$ and $\mathrm{C}$ has been shown to be numerically important only where overt infection is highly prevalent. The studies cited show that PCR analysis of serum or liver tissue can improve the diagnostic yield of conventional serology by $10-30 \%$ depending on the local balance of hepatitis B to hepatitis C. This would not have much impact for instance in South Wales and doubtless other provincial areas of the UK where chronic viral hepatitis is still uncommon. PHLS data for a population of 977000 in South West Wales showed that in 1999 there were only 44 positive tests for hepatitis B and 134 for hepatitis C out of a total of 16593 sera tested (Dr M Isaac, PHLS, Swansea NHS Trust). In this part of the world alcohol is a much more important cause of abnormal liver function, cirrhosis, and HCC although sometimes alcohol and hepatitis infection combine to give more advanced disease. ${ }^{6}$ The Dionysos study ${ }^{7}$ recording the prevalence of chronic liver disease in two towns in Northern Italy showed that there too, alcohol was by far the most important cause $(23 \%)$. Chronic viral hepatitis, although often associated with more serious disease, accounted for only $4.5 \%$ of cases.

Coeliac disease is another cause of chronic transaminase elevation that has come to light. It was found to be responsible for approximately $10 \%$ of apparently idiopathic cases 
from Italy in two recent reports. ${ }^{89}$ This should be an important consideration among populations of Celtic origin.

$\mathrm{NASH}$ has risen from obscurity and scepticism to great prominence over the past 20 years. ${ }^{10}$ This diagnosis was made in one in six of the cryptogenic Pamplona cases ${ }^{1}$ but there may be some dispute about definition. The diagnostic criteria put forward in 1990 by Powell and colleagues ${ }^{11}$ included alcohol consumption below $40 \mathrm{~g}$ per week. In Pamplona, NASH was diagnosed in patients drinking up to $80 \mathrm{~g}$ per day (that is, a 14-fold difference). This may reflect the more generous and tolerant attitude to alcohol in Spain. I suspect one man's NASH is another man's ASH.

Within a generation we have moved from labelling much or even most liver disease idiopathic to identifying a cause in over $90 \%$. The challenge is to find causes for the remainder.

Department of Gastroenterology,

J G C KINGHAM

Singleton Hospital, Swansea, SA2 8QA, UK

Email:jerry.kingham@swansea-tr.wales.nhs.uk
1 Berasain C, Betés M, Panizo A, et al. Pathological and virological findings in patients with persistent hypertransaminasaemia of unknown aetiology. Gut 2000;47:429-35

2 Cacciola I, Pollicino T, Squadrito G, et al. Occult hepatitis B virus infection in patients with chronic hepatitis C liver disease. N Engl f Med 1999;341: $22-6$.

3 Haydon G H, Jarvis LM, Blair CS, et al. Clinical significance of intrahepatic hepatitis C virus levels in patients with chronic HCV infection. Gut 1998; 42:570-5.

4 Brechot C, Jaffredo F, Lagorce D, et al. Impact of HBV, HCV and GBV-C/ HGV on hepatocellular carcinomas in Europe: results of a European concerted action. F Hepatol 1998;29:173-83.

5 Byron D, Minuk GY. Clinical hepatology: profile of an urban, hospital-based practice. Hepatology 1996;24:813-15.

6 Kingham JGC. Clinical hepatology: alcoholic liver disease, not viral hepatitis predominates in South Wales. Hepatology 1997;25:1297.

7 Bellentani S, Tiribelli C, Saccoccio G, et al. Prevalence of chronic liver disease in the general population of Northern Italy: The Dionysos study. Hepatology 1994;20:1442-9.

8 Volta U, De Franceschi L, Lari F, et al. Coeliac disease hidden by cryptogenic hypertransaminasaemia. Lancet 1998;352:26-9.

9 Bardella MT, Verchi M, Conte D, et al. Chronic unexplained hypertransaminasemia may be caused by occult celiac disease. Hepatology 1999;29:654-7.

10 James OFW, Day CP. Non-alcoholic steatohepatitis (NASH): a disease of emerging identity and importance. F Hepatol 1998;29:495-501.

11 Powell EE, Cooksley WGE, Hanson R, et al. The natural history of nonalcoholic steatohepatitis: a follow-up study of forty-two patients for up to 21 years. Hepatology 1990;11:74-80. 